\title{
Movements beyond human: Ecological aesthetics and knowledges in underwater wildlife documentaries
}

\author{
HEIDI MIKKOLA \\ University of Turku
}

\begin{abstract}
Our conceptions of underwater space are mostly based on images we have seen of it. These images, mediated through technology, have a great impact on how the environment is perceived. The article analyses how three different wildlife documentary series (Planet Earth, Dolphins - Spy in the Pod and Oceans) produce an oceanic environment and its inhabitants, and how these cinematic environments can affect how the ocean is perceived. The article's approach questions anthropocentrism and maps the relation between cinematic features, the oceanic environment and the aesthetic possibilities of perceiving more-than-human space. The analysis emphasises how the films' aesthetics are connected to the material movements of environments and animals. With the help of Gilles Deleuze's and Félix Guattari's concepts of assemblage and deterritorialisation, the article takes a posthumanist approach in mapping the possibilities of decentering the human and engaging nonhuman animals and nature as the proper cinematic subjects. The article argues that the audiovisual aesthetics of the analyzed documentaries are able to challenge anthropocentrism, but at the same time they are anthropomorphic in premissing their imagery on human comprehensibility.
\end{abstract}

KEYWORDS: wildlife documentary; underwater documentary; ocean documentary; film aesthetics; posthumanism; Planet Earth; Dolphins - Spy in the Pod; Oceans 
Compound eyes use different refractive indices, different materials, different fluids, to get something in focus. There is no better place to learn such things than in the immersive depths of the earth's oceans.

Donna Haraway: When Species Meet $(2007,263)$

\section{Introduction}

Our conception of life underwater has developed together with the technologies that have enabled filming deep under the ocean. Simultaneously, the abyss with its fauna and flora has become part of popular imaginary, enabling us to see the unseen environment. Wildlife documentaries visualise something that is beyond our (human) phenomenal world. These images of animals and nature have a great impact on how the environment is perceived and conceived. In this article, I analyse three different documentary series and ask how they produce an oceanic environment, and especially how the documentaries produce knowledge of the marine environment and its inhabitants through audio-visual aesthetics.

The audio-visual aesthetics produced in documentaries have an impact on what we know about these remote environments. In this article, I am especially interested in analysing the interaction between the humans, the animals, and the technology in this knowledge production. In my analysis, I pay attention to the ways in which zoe (animal life), bios (social life) and techne (technology, art) connect in the documentaries about oceanic environment, with the following research question: How is knowledge of the oceanic environment produced through audio-visual aesthetics created in the interplay between animals, humans and technology? By technology, I mean cinema and cinematic features, as well as the material technologies enabling the filming of and obtaining information on undersea environments.

Environments that used to be impossible to see, and therefore hard to imagine, are now part of our lives through technology. As Simon Cottle $(2009,508)$ notes, in his study on visualization of global crisis on the television news: "Geographically remote spaces become literally perceptible, "knowable," places of possible concern". Therefore, we need to have some kind of an encounter with inaccessible environments and events to be able to care. The deep sea, the abyss, is the kind of environment we could not see without the help of technology. The relationship between humans and oceans is almost always mediated through technology, be it audio-visual or of a more practical nature, such as a ship, scuba diving gear or a submarine (Crylen 2015, 14). In addition, 
on the open ocean, we are helpless without technology. As Haraway $(2007,249)$ suggests, technologies are not just mediators, but rather "organs, full partners" unfolding "the dance of world-making encounters". The materiality of nature, animals, humans, cameras, filming locations, film footage, cuts, and rhythms produce assemblages which create new material encounters; this could be a tangible encounter between a dolphin and a camera, a film crew and ocean currents, or a viewer's more virtual one with images of the oceanic environment. Elena Past argues that changing the filmic ecosystem to a marine environment, and emphasising the concept of the movement, makes people rethink their worldviews and paradigms (Past 2009, 53). The underwater environment is constantly on the move and the filming conditions underwater are very different from those on land. This provides an opportunity to rethink the concepts of humans, animals, and technology. Underwater films can help us conceive of a life beyond the mundane terrestrial environment and acknowledge the existence of very different lifeforms.

Cinema is an audio-visual media that can be seen as anthropomorphic, because in representing things to humans it generates subjects that are "more like us" or "less like us" (Ivakhiv 2012, 88, 96). In many cases, anthropomorphism results in a world view that places human beings in the centre of everything. However, as James Leo Cahill $(2013,74)$ states, even if cinema is an anthropomorphic apparatus, it does not have to be anthropocentric. It's possible to emphasise the ways in which anthropomorphism favours the potentials of transformations, the morphos (Cahill 2013, 74; Daston $\&$ Mitman 2005, 6). Cinema and other arts are also fundamentally zoomorphic because because their ways of expression often bring together humans and other living beings (Pick and Narraway 2013, 5). In the very beginning of the moving images in the late 1800s, animals were the first to be captured on film. Studies about animal motion were at the heart of developing the new medium. The first cinematic shots were not just of the movements of animals but also glimpses of water reflecting light, as in E.J. Marey's photographic studies of aquatic locomotion in the Mediterranean during the $1890 \mathrm{~s}$ (Shell 2005, 326). Hence, there is a resemblance between the ocean and the cinema: movement. However, underwater films have not attracted much academic interest in the field of ecocinema studies (Bousé 2000, xiii; Starosielski 2012,150; Crylen 2015, 7).

In this article, I analyse three documentary series, Planet Earth's episode Ocean Deep (2006), Dolphins - Spy in the Pod (2014), and Oceans (2008). I use close-reading and textual-visual analysis as methods to analyse the documentary series as cinema, as audio-visual apparatus, and as producing ecological, aesthetic, and affective compositions of nature and animals in the form of moving images. I understand images not only 
as representations but also as expressive and affective. I use Gilles Deleuze's and Félix Guattari's (2004) concepts of assemblage and deterritorialisation in rethinking dichotomies such as nature/culture and human/animal. My aim is to question the anthropocentrism of films and to look for visions beyond the human in these series, as well as to examine what kinds of epistemic issues do documentaries produce. This means that the approach is posthumanist (Haraway, 2003, 2008) in the sense that it maps out the movement of the human gaze and examines the possibilities of decentring the human from the middle to the margins. This article takes nonhuman animals and nature as the "proper cinematic subjects" (Pick \& Narraway 2013,8) that have an impact on audio -visual narration and aesthetics, spectatorship, and cinematic ethics. In the analysis, I want to emphasise and point out that the aesthetics of the films are deeply connected to the material possibilities of nature (Pick \& Narraway 2013,6). The material nature shapes and affects the technology used, as for example the movements of the camera are different in the undersea environment and on the surface, which also affects the aesthetics of the films. This affects how knowledge about animals and the environment is visualized for us. As Estelle Barrett argues, aesthetic experience functions as a system of knowledge production and knowledge appears as a "material process through interaction and action" (Barrett 2012, 63-4). In the first section of this article, I analyse how the episode Ocean Deep from the series Planet Earth produces knowledge about animals and how the series relocates the human in the oceanic environment. The second part of the article focuses on the series Dolphins - Spy in the Pod and its potential to challenge human centred aesthetics and knowledge production. In the third section, I discuss the series Oceans (2008), analyse the cinematic ocean as a compound of humans, animals, and technology, and direct the discussion towards knowledge of ocean environment and a critique of anthropocentrism.

\section{Life beyond humans: BBC's Planet Earth}

In this section, I analyse one episode from a BBC's series Planet Earth (2006), Ocean Deep, which is the only episode of the series that focuses on the deep sea. Planet Earth has 11 episodes, each about 50 minutes long. The series can be considered, at some level, as a so- called "blue chip" -documentary (Bousé 2000, 14-15). Blue chip-documentaries have a high production value, humans and their habitats are framed out of the image, and environmental politics are avoided. Usually, the dramatic story lines, using voice-over narration, deal with megafauna such as large mammals without any historical reference points. In Planet Earth, the environmental issues and the survival 
of the species are discussed at some level. Derek Bousés definition of blue chip was published in 2000, at a time when wildlife films did not have an explicit conservational discourse as they have today (Richards 2013, 1-2). As Morgan Richards (2013) states, wildlife documentaries have recently gone through a change towards being "green chip", where the genre's position with regard to environmentalism and climate change science has become more composite. As discussion on general environmental issues became mainstream (for example in advertisement) in the mid 2000s (Cottle 2009), so in Planet Earth environmental issues are discussed or at least mentioned - by contrast, for example, to another BBC large scale production five years earlier, The Blue Planet (2001). This section analyses how Planet Earth produces assemblages of the underwater world and knowledge about it in cinematic ways, focusing on the animals, and also how the series relocates humans in this environment.

In my analyses, the concepts of assemblage and deterritorialisation are important when considering movement in the aesthetics of the underwater environment. For Deleuze and Guattari $(2004,556)$, an assemblage consists of content and expression as well as of territoriality and deterritorialisation. By assemblage, they refer to rhizomatic structures and the unmaking of dichotomies like nature/culture, human/nonhuman. Concepts of nature/culture and human/nonhuman are deeply connected to each other and cannot be seen as distinctive but rather as including each other. In this process of inclusion, deterritorialisation is the process of creating new encounters and assemblages that alter these binary distinctions. For Deleuze and Guattari, territory is an order or a system, while deterritorialisation is a process of secession or an expansion of a territory. Reterritorialisation is a formation of a new territory, where things form a new composition. Because audio-visual aesthetics under the surface function by a different paradigm than visualizations on land, underwater documentaries may have the potential to decentre fixed categories. Deleuze's and Guattari's concepts do not refer to the essence of things, but emphasise movement and change, thus being useful for conceptualizing ecological connections (Herzogenrath 2008, 4).

In Planet Earth the aesthetics produce conventional repetitions or refrains of underwater environment, with only a few scenes creating deterritorialisations in narrative sequences. Sir David Attenborough narrates the images of nature and wildlife, mostly without any appearance of humans. The music is composed especially for the series and played by the BBC's orchestra. The episode starts its journey to the abyss from the surface with David Attenborough narrating: "Away from all land. The ocean. It covers more than half the surface of our planet and yet, for the most part, it is beyond our reach. Much of it is virtually empty. A watery desert." The framing of the image is 
from above the clouds and moves forward with blue sea covering the whole frame. The narration implies the ocean is something totally different from the land and that it is far away from human habitat, out of our everyday access. Images of the scene create an environment that extends over the image frames as repetitions of glimmering and blue without focus points for a gaze to follow. The scene creates distance between humans and nonhumans, marking the ocean as something that is either mostly uninhabited, or inhabited by lifeforms unfamiliar to the viewer. The ocean is exoticised as a mystery that we do not know everything about, a place away from culture and humans, where the documentary, however, is taking us and giving a possibility to see the unseen. The scene introduces a romantic paradigm about nature, as a source of wonder, beauty and harmony (Jeffries 2003; Cubitt 2005).

The beginning of the film has a very slow and calm tempo, showing whales, sharks and fish swimming in harmony in a blue ocean with the accompaniment of peaceful orchestral music. The programme creates an oceanic time that is different from the hectic tempo of the land. The rhythm changes with a narrative sequence with dolphins, which starts with an aerial shot of a school of dolphins racing on the sea. The narrator describes the dolphins' movements as "Excitement far from land", and the music becomes upbeat and cheerful. As the dolphins are hunting mackerels the camera moves in the middle of the school under water. The narrator takes long pauses in his speech, while the sounds of splashing and bubbles as well as the voices of dolphins provide a soundscape merging with the background music, like a nonhuman poetics of the movements of animals and technology without human speech. The sequence departs from the classic mise-en-scène of 180 angles, as fish and dolphins as well as birds from above the surface dive in all directions, emerging from and disappearing behind the camera. The action does not take place only in front of the camera but also behind it, producing the impression that the viewer is part of the event and it is not just being performed in front of the camera. Sensations of water and movement are highly present in the scene. The scene produces sensations such as the water pressure under the wings of the birds when they rise up to the surface from a dive, as well as the sound of breaking the surface and gasping air. Sounds, like the birds' utterance and the sounds of breaking the surface at the end of the scene, indicate a rising above the surface, while the image stays under water and starts moving down and forward; the sounds above the surface are not visually actualised, although they expand the framing of the image and territory above the surface. In this way, the scene bundles together the realms above and beyond the surface into a coherent space as an animal habitat, thus deterritorialising the surface's human centred liminal status. The scene shows the marine habitants not as if 
they were in an aquarium, in front of the human eye, but in an ocean space that is active and expanding and not just limited to the underwater. Knowledge is not bound to exact facts about the behaviour of the animals on the screen, but the scene rather produces material sensations and brings the viewer closer to the underwater assemblage.

Connections between the land and sea are also created in the previous sequences, which handle shallower parts of the sea; on the surface, the deep sea is represented as a mysterious zone for very different kind of lifeforms. The necessity of technology to be able to reach this environment is also emphasised. The lights of the submarine break the illusion of an oceanic kingdom without intrusion of humans. As the lights slide into the frame from below, the narrator relates that "Below 500 meters, new mysterious animals appear." In the frame, a translucent creature swims by. Then comes a cut to another creature, which is described in the following way: "Their bizarre shapes help them to remain suspended in the dark space." Then a cut to yet another strange creature, and the narrator continues: "Some resemble creatures familiar from shallower waters. Others defy classification." The pace is very slow and has almost the feel of slow motion, defamiliarising the creatures. None of the creatures are mentioned by name. The lack of information is unusual because viewers are used to being told facts about what they are being shown, at least the minimum knowledge of the name of the species. However, these animals do not need to be objects of human knowledge to have the right to exist, as Cubit $(2005,57)$ points out. Even though the creatures are shown swimming slowly in front of the camera, the narrator stresses that the animals themselves would actively "defy" human classification. The language the narrator uses to describe the deep sea creatures also emphasizes their strange features, but also explains their adaption to the deep sea environments and the functions of these features.

Knowledge production about the abyssal zone is linked to the animals, who usually one by one appear in the frame as the voice-over articulates facts about them, such as anatomical explanations about their adaptation to the conditions around them. In one scene a dumbo octopus swims into a spotlight in front of the camera in a close-up. The image is sharp with the skin and wrinkles of the octopus visible while its tentacles move. After a cut, there is a shot of what is described as "The weirdest in this world of the strange, Vampyroteuthis, the vampire squid from Hell." The lights of the submarine are switched off so that the octopus's own lights in its tentacles become visible. The scene is first illuminated by technology and then by the animal itself. The scene is defined by a play of light and darkness, and the soundscape is constructed by deep industrial ambient noises, as if from outer space. In these scenes, creatures from the abyss are shown in the frame one at a time, straight in front of the camera, separated from their habitat. 
The environment is an active agent and has an impact on the aesthetics of the film, like the darkness of the environment to the human eye. The human is a bystander in many cases and the independence of the environment is often emphasised. The camera glides forward along the sea floor and focuses on an underwater volcano, which has an independent ecosystem around itself. There is a shot of shrimps feeding on nutrients erupting from the volcano. The narrator says: "So, beyond the farthest reach of the Sun's power, a rich independent community exists that draws all its energy directly from the Earth's molten core." The size of the volcano is described as a "three story house". The scale is compared to familiar everyday objects to demonstrate the size, bringing social or cultural connections to a deep-sea environment. The viewer depends on the narrator's descriptions about the scale of the things on the screen (Prescot-Steeds 2008,40 ). Things can be massive or tiny as a particle without a chance for the viewer to notice the difference in size. This emphasises the potential of the moving image and the framing to alter the usual dimensions observed by human senses. The scene differs from the program's earlier visualization of the deep sea since it shows many animals together, while the animals in previous sequences have appeared mostly one by one during a shot. In many of the scenes in the volcano sequence, the image creates a sense of floating, and there are no fast cuts. The images are blurry and there is no sharp focus: the water is so hot near the hot vents that the image seems to flicker, even though Planet Earth is shot in HD. The otherness of the abyssal zone is emphasised by the camera's slow movements and cuts. This differs radically from the films of Jacques Cousteau, in which the underwater realm was represented as faster and as more mobile, and at the same time as a space completely dominated by humans. The slowness of the abyssal zone emphasises its nonhuman character, a territory that is not under human management. The aesthetics of the audiovisual narration do not create an illusion of an ocean dominated by humans, but instead portray the sea as a place of very different lifeforms and the human as an outsider. In Planet Earth, the underwater space is presented as different from life on land. However, the differences here emphasise movement in different directions, which creates contacts between the environments and does not compose them as simply in opposition.

The voice of David Attenborough territorialises the underwater movement. It gives coordinates to the viewer by naming the places of the events but at the same time it ignores the flux of the oceanic environment, which is constantly moving. Here, framing the movement is not just a matter of giving lateral coordinates but also vertical ones, as the narrator locates the events underwater. The rhythm of the sequences and the territorialisation of the place also vary depending on whether the location is 
in the deep or on the surface. In scenes near the surface, the establishing shots are introduced from an aerial perspective, while in the deep, a shot of a submarine might be the actual establishing shot and thus emphasise the importance of technology for humans in these environments. The soundscape of the underwater world is mostly created in postproduction, meaning that the sounds are recorded and added later to suit the images. The underwater world is also a space where the ability of humans to hear is very limited, so the audio world of the underwater space has to be recreated for human ears. When it is a matter of a familiar animal that the viewer will most likely recognise, such as a mammal or a shark, the music is usually affective in that it can be recognised as, for example, joyful, calm or thrilling. However, when we see images of small organisms or other "strange" deep sea creatures, the music becomes more ambient, and creates associations with outer space. As Cubitt $(2005,55)$ notes, sounds and images of the deep sea are associated with science fiction and horror - genres that customarily employ special effects: "The farther it [the visualization of deep sea] strays into domains where humans can only survive protected by advanced technologies, the stranger both sounds and musical elements become." Soundscapes create territories for different animals as well as for viewers. Music has a great impact on how viewers perceive the images, through its function of creating a familiar space or a recognisable environment for the viewer (Pisters 2003, 190). However, in the case of the deep sea, the "recognisable environment" is associated with something else than the actual environment. The ambient sounds of the abyss are more associated with outer space than the underwater world and this produces a correspondingly remote territory. However, these produced territories are not so much connected to actual environments as to the animals that are in the frame. The images therefore produce territories in relation to specific animals. Knowledge about the underwater environment is connected to the animals in the frame, not so much to the environment as a whole.

The problem that blue chip films, like Planet Earth, usually have, is the framing out of any traces of humans. In this particular episode, Ocean Deep, the viewer is aware of a submarine in the picture but otherwise humans and technology are invisible. Framing out the humans implies that there is a pristine natural world independent of human action (Bousé 2000, 15). The submarine itself is shown only briefly, only its lights are visible for viewers in most of the takes. As Greg Mitman $(2009,4)$ has pointed out, we as viewers want to experience the pristine nature, yet the experience is impossible without the interference of technology. The episode ends with the notion of whales' dependence on plankton as they are seen swimming on the surface of the blue sea that covers the whole frame. The narrator states: “Once, and not so long ago, 300000 blue 
whales roamed the oceans. Now less than three percent of that number remains. Our planet is still full of wonders. As we explore them, so we gain not only understanding, but power. It's not just the future of the whale that today lies in our hands, it's the survival of the natural world in all parts of the living planet. We can now destroy or we can cherish. The choice is ours." The voice-over brings in the problem of humans just at the end of the episode, although it is only on the level of the narrative voice that it is problematized. Humans seem to have power over the sea through their knowledge not as "dominators" but rather as "stewards", a change in attitude towards the oceans pointed out by Messier and Batra $(2008,8)$. The otherness of the underwater world has given the western world the permission to take advantage of the sea for centuries. Although the narrator is the only human present in the episode, the episode does try to create a contact between the terrestrial and the underwater worlds and deliver the fact that human action has an effect on the oceanic environment. Planet Earth creates romantic notions about the wonders of the natural world, although the ocean is not seen as a stable, never-changing entity, but rather the change is emphasised. In the series, knowledge is produced through the animals, who reveal the secrets of the oceans to humans. Nature's processes are seldom discussed without the appearance of animals in the frame. The sea and its living creatures are exoticised as something other than life on land, but the creatures and the sea are not treated like colonial "subjects that are fully understood by the experts who have come to record them and whose exotic lives can and must be explained to the viewer" (MacDonald 2006, 16). The ocean environment is also seen as something that avoids our knowledge and as hard to obtain - always on the move - although the knowledge itself is seen as a valuable tool in acquiring the power to save the oceans.

\section{Aesthetics beyond anthropocentrism: Dolphins - Spy in the Pod}

In this section, I analyse Dolphins - Spy in the Pod (2014), a two-part series produced by John Downer Productions and distributed by BBC One. I discuss the audio-visual aesthetics of Dolphins - Spy in the Pod and its potential to challenge human centred aesthetics and knowledge production. In the programme, remote-controlled cameras are hidden in animal-like "spy creatures", which look like a turtle, a dolphin, a puffer fish and a squid, and they swim on the surface or dive into the deep underwater to film the life of dolphins. In the second episode, there is also a camera attached to the back of a tame dolphin, which swims freely and connects with other dolphins in the Caribbean, thus joining the viewer's perspective to the dolphin's movements. A camera attached to an 
animal cannot generate an “immediate experience of otherness", as Haraway (2007, 252) points out, but it can produce imagery and framing unfamiliar to audio-visual narration, and so glimpses of a world not controlled by humans. Haraway $(2007,261)$ also states that a camera carried by an animal reveals the animal's social behaviour when no humans disturb their space. This is also the case in Spy in the Pod, where the dolphins interact with each other and with the cameras in a way that provides quite an unusual imagery.

The programme focuses on only one species, dolphins, making the dolphin into the main character of the series. This creates quite a narrow image of the oceanic environment, although a few other species like whales, sea lions, and even a few humans are shown. The voice of the narrator, David Tennant, explains the dolphins' habits and the new discoveries (not common knowledge) about their behaviour that were made during the filming. In some cases, the voice-over narration creates a contrast to the audio-visual material of the series, causing an anthropomorphic view into dolphins' lives; for example, the narration covers a new-born calf growing up with his mother and other female dolphins, finding a gang of bachelors to join and finally discovering a girlfriend. From time to time, the voice-over is silent and the viewer hears only the sounds of water and the dolphins' utterances. It is not just the dolphins who have humanlike features, since the narrator uses "he" of the spy creatures and talks as if the cameras have a mind of their own. However, the strength of the programme lies in its aesthetic visualisation of life under (and on) the surface, as well as the creation of an underwater soundscape. The aesthetics of this production differ from the underwater imagery of Planet Earth mostly because a different kind of filming technique is used. At the same time, the series operates according to a paradigm of "reality", in a sense that it presents a type of found footage with shaky image and sound that seems like a live recording.

The framing in Spy in the Pod is more random and out of focus compared to Planet Earth, and close-ups of the dolphins' skin are common, as is also the camera's easy movement under the surface. After an introduction to the series, the programme starts with a high-speed take of dolphins rushing forward on an open ocean. The camera goes underwater and back to the surface in rhythm with the dolphins. After this fast-pace take, the camera dives down under the surface with the pod, the colours taking on a blue hue. A spy creature resembling a puffer fish swims out of a large shell and the dolphins take an interest in it. The image takes the perspective of the spy creature and we see close-ups of a dolphin's nose while it takes a closer look, straight at the camera. There is no background music, only the sounds of the water and the dolphins. The soundscape is not dominated by orchestral music as in Planet Earth. The audio world is produced by the dolphins' squawks and chirps, splashes and rushes of water, 
and only occasionally light non-diegetic music, which does not take over the image and tends to emphasise the underwater environment beyond human influence. This take, along with the whole series, makes technology visible not only for the viewers but to the animals in the image as well. It emphasises the possibilities of technology not physically equipped by humans in deterritorialising the visualization of an underwater environment. When animals look at the camera, it deterritorialises the viewer's gaze and enhances the feeling of "reality", the sense that the action and events on the screen are not just staged for the viewer to watch but are real material encounters in the underwater environment. Technology is not just a mediator between animals and humans but a "full partner" (Haraway 2007, 249) in the underwater assemblage.

The ocean is a smooth space as defined by Deleuze and Guattari $(2004,528)$ : "Smooth space is filled by events or haecceities, far more than by formed and perceived things. It is a space of affects, more than one of properties. It is haptic rather than optical perception." This kind of space has great potential for deterritorialisation (Deleuze \& Guattari 2004, 530). Dolphins - Spy in the Pod produces haptic sensations for the viewer. As Estelle Barrett $(2012,64)$ states, "Aesthetic experience operates as a mode of knowledge production". Knowledge appears through these material encounters and interactions, which involve an affect and a sensation of an aesthetic experience (Barrett 2012, 64-5). The images follow the rhythm of the animals, whether they are jumping above or below the surface, swimming at high speed, or calmly searching for food. It creates a nonhuman rhythm at the centre of the film's audiovisual aesthetics and deterritorialises the visuals as regards what is to be known and expected during the film, thus creating new assemblages. The cameras and the spy creatures, together with dolphins, become the central protagonist in the series. This decentres the humans and places them in the margins, away from the focus point, and this not only in the images but as agents producing the visual material. Here, what is known is something that technology shows us.

Spatial coordinates in an oceanic environment are hard to point out visually for the viewers, because the underwater space appears as generic (Crylen 2015, 11). When the narrator talks about the location where a sequence is taking place, there is usually an establishing shot above the surface showing the horizon with a long shot. This is a typical method for locating the place before the narration begins. However, it is also a territorial movement framing an anthropocentric view of the ocean. As Steinberg states, "locating" an oceanic event in a single place simplifies the oceanic environment, its boundaries and events $(2013,162)$. Since these long shots above the surface are used quite seldom in Spy in the Pod, they tend to stand out from the images shot below or on the surface. However, not all the establishing shots are above the water. Some of 
these shots are under the surface and the only evidence of the location is the narrator's voice naming the place. In these sequences, there is no visual difference between the underwater environments. The change of location is more like a liquid continuation of the previous sequence, with no visual forcing of the framing and localisation of the human-eye perspective. The sequences are much longer than in Planet Earth, where a single sequence is about 4-5 minutes long. In Spy in the Pod it is not easy to specify the length of one sequence because the takes are blurred into each other and because the visual narrative structure focuses on the action underwater, which makes the images and takes liquid and immersive. There is a movement towards spatial reterritorialisation when the camera dives underwater and the aesthetics, sounds and colours change. The soundscape varies depending on whether the camera is below or above the surface. When the spy turtle is first introduced, it is swimming with dolphins and moving along and below the surface. The changing soundscape within the same take produces a reterritorialisation. When the spy turtle's head is being framed on the surface, the sounds are of rippling water, but when the perspective goes below the surface, the sounds become muffled and bubbly.

Haraway $(2007,258)$ points out that the unusual perspective in Crittercam, a National Geographic programme which uses small cameras carried by animals, is like the first-person perspective in a videogame. In Spy in the Pod, the cameras swimming with the dolphins, especially the one the dolphin is carrying, likewise produce a first-person perspective for the viewer. It is also common in many other shots of the oceanic environment (and not just in Spy in the Pod) that the camera moves to produce a first-person view or "an affective ego perspective" (Galloway 2006, 58), which is not the case in land-based shots. In the imagery of the underwater the feeling of space is different, more mobile and three- dimensional, than on land. In the sequence which contains film material from the camera carried by the dolphin, the image goes up and down in rhythm with the dolphin's movements while it swims and jumps. We see a jumping dolphin, a quick glimpse of an island, bubbles and splashes, some seaweed, the sea floor, the dolphin's skin, flying birds, and the sun shining on a surface. There is no music, just the sound of water. The sequence takes just a little over a minute, then comes a cut and a steady long shot of a dolphin diving along the surface, and the visual narration is presented in a more traditional way again. Without the voice-over narration, this kind of imagery would not make much sense, as Haraway $(2007,258)$ points out. The sequence is about sensations like speed, the touch of water, and the movements of a swimming dolphin. When technology and animals are used to obtain imagery like this, the technology and animals are also, in a way, using the humans who must adapt to the 
nonhumans' specific needs (Haraway 2007, 262). While it is indeed the case in all of the series discussed in this article that knowledge is produced through technology, in Spy in the Pod this is not only visible but emphasised. The documentary engages with the world through technology. Knowledge is produced by the cameras that show us the animals' interactions and thus attune the viewers to the oceanic world.

On the screen, we see mostly dolphins and the technological spy creatures, although humans are not completely framed out. One sequence, in which the dolphins rush to a fishing boat to feed on what the fishermen throw overboard, shows humans mainly as just an easy source of food. In another take, the dolphins swim next to a boat because "they enjoy the free ride" of the boat's waves, as the narrator tells us. In the sequences, in which orcas are swimming to their feeding ground in a bay, there are houses on the shoreline and a harbour in the background. Hence, humans and their habitat are just a background for the animal action. Humans are present in the oceanic environment but just on the margins of the dolphins' habitat. Dolphins are represented as the "people of the sea", as having different cultures depending on their geographic location, and as being highly social and curious. In addition, knowledge among the dolphins is emphasised; they pass on their knowledge, such as fishing techniques, to each other. In some cases, it is pointed out by the narrator that what is new knowledge to us is not necessarily a "discovery" in the colonial sense (MacDonald 2006, 16): "This is the first time such an extraordinary gathering of sea creatures has been recorded, but to the worldly-wise dolphins it must be a common sight." This implies that there are other knowledges in the world beside human knowledge. Some images in the programme have a view that is other than human: they are randomly framed, lacking a focus point, and as such difficult to interpret. These rhizomatic images are "between things", capturing moments when things from the margin move into focus with the intention of "encouraging viewers, too, to reposition themselves" (Past 2009, 64). The aesthetics of Dolphins - Spy in the Pod creates underwater sensations and intertwines the viewer into the underwater world in such a way that life under the surface becomes the centre of things while life on land seems marginalised. The oceanic assemblage evoked by the series deterritorialises the perspective from the human-centred world towards the lived bodies and rhythms of animals underwater. While humans are in contact with the oceanic environment, the emphasis is on the nonhuman agents and their contacts with each other and with technology. The images decentre humans from knowledge production. The sea becomes understood as a social environment, not only for humans but for animals as well, thereby normalising the underwater space into a lived-in environment and deterritorialising the viewer's terrestrial, land-bound self. 


\section{The underwater ethics of Oceans}

In this section, I discuss Oceans (2008), an eight-part series produced by the BBC and Discovery Channel. The series is like a travel log with a strong environmentalist tone, a documentary not so much about the fauna of the oceans but rather about the state of the world's oceans - and a critical evaluation of the human impact on them. The series engages with a marine environment as seen through human action. I analyse the cinematics of Oceans as a composite of the human, the animal, and technological and as a turning point in the discussion towards the critique of anthropocentrism and human-centred knowledge of the ocean environment. My objective is to demonstrate that the oceanic environment is not outside of culture and social life, that the nonhuman is not non-historical as is often claimed (Pick \& Narraway 2013, 8).

In Oceans, a team of explorers - including the expedition leader Paul Rose, maritime archaeologist Lucy Blue, marine biologist Tooni Mahto, conservationist Phillippe Cousteau Jr. - travel to different oceanic locations to survey environments and marine life. There is a voice-over narration throughout the series, but the programme also uses the talking heads of the crew members. At times the crew film underwater, but mostly they are on the ship trying to find animals to film. The explorers also meet difficulties in their attempts to dive under the water and they are presented as being totally dependent on the technology on board. Oceans has a more scientific paradigm than the romantic notions of nature in Planet Earth and Dolphins - Spy in the Pod. Oceans' paradigm is characterised by "change, crisis and challenge" (Jeffries 2003, 532), a searching for facts and proofs about the oceans' condition, and also the taking of action to save the oceans and obtain knowledge.

In the first episode, The Sea of Cortez, the crew is shown watching film footage of hammerhead sharks on a laptop, filmed 16 years ago (from the time of shooting the series) at their present location. The viewer is told that the shark population is in decline and that nowadays they are hard to find. The film footage is first shown to the viewer on a full screen, implying that it is shot for this documentary or "this moment", instead of evoking the timelessness customary of images in wildlife documentaries (Bousé $2000,15)$. However, it is soon revealed that the footage is old. This discloses the idea of the ocean not as a timeless entity but as a changing environment which has history, and on which humans have had a negative impact. The same idea is repeated later on in the series, in Episode 5, when Philippe Cousteau (a grandson of Jacques Cousteau) speaks to the camera during a filming of coral reefs in the Indian Ocean: "Having grown up with images of my grandfather's films and my father's films, back in 1948, and you 
look on that, even if it's black and white, it's like an amazing forest, just... Richness is unparalleled. And you go back to those same places today and it's just a desert." Here film technology functions as memory, recording events in the past and bringing them to the present as active images revealing the change that has occurred. The moving image works here as a scientific tool for visual evidence of the ecosystems, producing knowledge instead of notions of nature's richness and "wonder", as in Planet Earth.

Visually Oceans does not present the spectacular imagery and wondrous nature of Planet Earth, but rather a diverse and unexpected image of the sea. The viewer is directed to the ocean not by dolphins or other animals, as in Spy in the Pod and Planet Earth, but by humans and their reactions. Emotional affects are produced not so much with spectacular images, as in Planet Earth, or with cinematic techniques, like music taking control of the image, but more through the crew's reactions - the excitement of seeing a group of whale sharks or the frustration and anger when watching shark catchers. The crew members are the main characters of the series, even though the focus is on the oceans and their fauna. The oceanic environment is not just a background for human action, but instead the humans, oceans and animals become tightly combined in the environment's rhizomatic structures. In the introductory sequence to every episode, the expedition leader Paul Rose says to the camera: "We are here to try to understand the earth's oceans and put them in a human scale." The statement implies that there are other, nonhuman scales as well, which are also emphasised during the series, and this involves technology as an instrument for understanding.

Even if the crew members are the main characters and active agents in the series, they are not in control of the sea or the animals, and therefore from time to time are represented as bystanders to the actions of the animals and the environment. The crew faces difficulties on their expedition because of the swelling sea, tropical storms, sea currents, or technology-related problems that they do not have control over. They study animals, but the animals study them as well, thus changing the point of view. In the first episode, the crew members are seen swimming with the whales after studying whether the animals have caught any human bacteria. Marine biologist Tooni Mahto is scanned by a whale's sonar and comments: "I heard and felt that pulse just, boom, going right through my body, as it was doing the kind of X-ray scan of what the heck I was." Here, whales and humans are combined on many levels: they do not just share the space, they may share the same bacteria, and both are studying and looking each other. In Episode 2, there is a sequence with sea lions swimming very close to the divers and taking great interest in the cameras, which prompts Tooni to note: "You see how much of a good look they're giving us. Really, really looking." Here, animals are not just 
objects of study and observation, but also active subjects in their own environment. In these sequences, as the animals look straight into the camera, even the viewer has the feeling of being the subject of their gaze. The point here is the changing perspective of who is looking at whom, the movement between these compound gazes between humans and animals, and the deterritorialisation of the gaze.

Without technology, the crew's human bodies cannot encounter the underwater realm for long, since in order to stay below the surface they need technology and oxygen. In the first episode, Paul is seen preparing for a dive to search hammerhead sharks using special dive gear that does not produce bubbles, since sharks are easily scared. Here, sharks are acknowledged as subjects in their own right, as having an agency that leads to changes in technology to suit them. For the following three days, the crew is seen diving and trying to spot sharks, but they cannot find any. Some animals are hard to find and not overrepresented as usually occurs in blue chip films (Bousé $2000,15-16)$. Consequently, in this series, a general problem of wildlife documentaries is disclosed through images of divers trying to find animals to film. On the other hand, as mentioned in the previous chapter on Planet Earth, humans are underrepresented in wildlife films (ibid., 15-16), which creates the impression that there are a large number of animals, even endangered ones, living outside any human presence "out there" in nature. The series does not frame the humans out from the environments they are filming, but represents the humans as a part of the history of specific ecosystems. Anthropocentrism and the division between human culture and animals can be challenged not just by creating a territory for animals and removing the humans from the image, but by emphasising the rhizomatic structures, complex interactions and assemblages that humans and animals make with the environment.

In the second episode, there is a discussion on how the warming waters of the Southern Ocean are affecting the Tasmanian kelp forest. Tooni Mahto states: "People don't care about kelp. Everyone's worried about the dolphins and the whales, and they should be worried about the kelp because they are the ecosystem engineers. [...] You've got to look at the ecosystem, you can't just pick one species and attempt to conserve that because it doesn't work." Here the popular knowledge about the ocean environment is criticised for focusing on large mammals that are easy to relate to. In the episode, the problems are not only raised but there is also an attempt to find a solution; the crew members are seen working in a research project to restore balance to the kelp forests by reintroducing lobsters that fishing has wiped out from these ecosystems. Knowledge is produced through visual evidence and as social practices that present us with changing oceanic assemblages. 
In a sequence in Episode 4, where the crew is seen attaching identification tags to a shark, the image is shot from underwater even though the action takes place on surface. This produces a nonhuman view from deep under the surface, as if something was watching humans in action from afar. The space in the sequence extends upward to produce an unfamiliar perspective, showing the boat's bottom and the shark, while human figures are blurred and out of focus above the surface. The same kind of perspective is also used in an underwater take in which Paul places an oceanographic device on the Argo float to measure the temperature, salinity, and currents. When he releases the Argo float, the camera is high above him, filming downwards while the machine sinks down to the sea floor, which is not visible. The take creates a feeling of vertigo, because the space just keeps expanding downwards into blueness without any focus points. The underwater space is here deterritorialised beyond the human viewpoint as a space without cartographical focus points or means of identification. It is about the movement and volume of water masses, the continuum of water. Without a territorialising voice-over locating the images underwater, images are usually in blue hues and clear. The watery space itself does not seem to have a specific character by which to identify some special location as in Spy in the Pod. However, in Oceans the colour of water varies in many locations. These colours, whethergreen and hazy, blue, turquoise, or even red and orange, are unique to each location and their causes explained either by the voice-over or the talking head of the crew. Even though from above the surface the colour seems to always be the same, when diving and filming underwater a variety of colours appear. The ocean's materiality and rhizomatic structure becomes visible in these scenes, which show the sea to be not just salty liquid but an interaction of sediments, nutrients, light, and currents, etc.

Haraway $(2007,263)$ states that animals, humans, and technology are all part of the meaning-making processes: "They touch; therefore they are. It's about the action in contact zones." These contact zones are symmetrical in the sense that animals are no more passive bystanders than humans are, and animals also create challenges for humans and technology and vice versa. Throughout the series, the land and the sea are seen as continuous, in the same contact zone. As the marine biologist Tooni Mahto says in Episode 6, "The sea can never be considered to be a discrete entity from the land. The two are completely interconnected, and nowhere more so than the coastal zone." It is emphasised that human actions on the land necessarily have their effect on the sea, with images of coastal zones demonstrating the changes caused by humans. As Steinberg $(2013,163)$ notes, the sea is considered as the outer and the land as the inner territory, with coastal zones being something in-between and able to question the land-sea binary. 
Space is also defined according to whether it's above or below the surface, which is a kind of "threshold" for human action. In a sequence where Philippe and the maritime archaeologist Lucy Blue are diving into an underwater station for oceonauts, built in the 1960s by Jacques Cousteau, Lucy notes the following: "But it has a real sense of being placed here deliberately, and that is what's such a contrast to what I usually find in terms of the remains of human culture or activities underwater, where they've happened to end up there by default." The remains of human action are usually there by accident, like wrecks or trash. Our actions are a part of marine space, although the underwater space is not a place for deliberate signs of humans but rather indicates accidents, carelessness, and ignorance. One example of this is the case of the lion fish, presented in Episode 4, where it is stated that although the lion fish is not native to the Atlantic Ocean, it is now threatening the native species in this area. Originally the lion fish were pets that have been released into the wild during the last 20 years. The marine space is unintentionally shaped by human action, which becomes a part of the ecosystems in these contact zones. Furthermore, this also demonstrates the ethics: even though animals are as active agents as humans, the effects of animal and human agency are not in balance (Haraway 2007, 263). However, it is also pointed out in the series that because of varying circumstances, not all people are in a position to make the best ecological choices.

It is in these contact zones, where encounters are created with different environments and forms of life, that film can enhance ecological thinking. In Ocean, the crew are seen studying the naturecultural (Haraway 2003) history of the oceans, where human action is cannot be wholly separated from the processes of nature. The ocean is seen as a mediator between different lifeforms, and knowledge production is seen as a social process - not just for the sake of bios, but as a process that involves zoe and techne as well. In a way, Oceans has the same idea of knowledge as that introduced at the end of Planet Earth: gaining knowledge to save the oceans. However, in Oceans, knowledge is seen more as a process that involves bios, zoe and techne, than as a form of power as in Planet Earth.

\section{Conclusion: Towards a more-than-human vision}

I have mapped the concept of more-than-human aesthetics, outlined how knowledge is produced in the three documentaries, and examined the way they assemble spaces for different lifeforms. The more-than-human approach affirms the potentiality of the oceans as well as the cinema to conceptualise the environment and its habitants as 
active agents in filmic assemblages, highlighting the fact that the environments are fundamentally shared with other lifeforms and we must take them into account. This approach emphasises animals as active agents in the filming process and in the production of aesthetics and knowledge, not just as passive objects to be filmed and observed. Just as the animals are not there just to be looked at, the environment is not a mere stage, where the action takes place, but rather an integral agent in the aesthetic processes. This is demonstrated by the dark and flickering images of the deep sea chimneys or the variety of colours appearing under the surface due to sediments or sea currents. Even if the final aesthetic choices are in human hands, images can reveal something of a world unseen by the human eye and out of human control; images such as the wrinkles on the skin of the octopus, visual material from the dolphin's camera, or the expanding underwater space. Images present the movement of the ocean and the rhythms of animals, and allow us to perceive them.

Planet Earth produces perceptions of the marine environment through animals as individual species as well as romantic notions of nature as a "wonder". However, the connections to human action and the human impacts on the oceans are mostly ignored. The illustration of animals and the oceanic environment produce spectacular imagery, but mostly keeps a conventional distance to the viewer, allowing us just to admire beautiful images. Technology is introduced as a tool that enables filming in the challenging environment of the abyss. Knowledge is seen as a valuable tool for saving the oceans. The underwater aesthetics of Dolphins - Spy in the Pod, on the other hand, create haptic sensations and produce knowledge through technology, which is a vital part of the filmic assemblage. The series also has romantic notions of a wonderous nature, but the aesthetics support the feeling of "reality" as humans and technology are also part of the environment. This series deterritorialises knowledge as well as aesthetics into more mobile and less rigid forms. Knowledge is not something that only humans possess but is also shared by other animals. In Oceans, zoe, bios, and techne are all part of the knowledge production, even though the series engages with the ocean through humans and human action. The documentary adopts the paradigm of "change and challenge" in order to gain knowledge about saving the marine environment, and the oceans are seen as assemblages of rhizomatic connections. On some level, all of the three series tackle the questions of change and movement. They take different approaches to animals, technology, and humans, but all of these moving images produce a sense of the more-than-human world and place humans away from its centre. When it comes to the ocean environment, cinema is an excellent apparatus in bringing the material environment closer to us, because it reveals the ocean's movement in time and 
space. In all three series, the underwater aesthetics are different from the aesthetics on the land. The underwater images are more mobile and the construction of space is different. In the ocean, the filmic space deterritorialises the habits of land-based aesthetics.

Wildlife documentaries have a strong role in creating environmental values, as Greg Mitman (1999) has pointed out. They are often the only connection viewers have to the environments and animals they represent, such as creatures from the deep sea. Moreover, these films, like most episodes of Planet Earth, often try to hide the technology in order to represent nature as authentic and without human or technological interference. Still, it is the technology that enables us to see and experience the virtual images of nature and animals. Popular global imageries, whether they are images of wildlife documentaries or news reports of threatened environments, function as "icons of globality" of the shared planet (Cottle 2009, 507). However, these images are more than just icons, since the images create an affective connection to the environment and its habitants. The politics of wildlife documentaries, as of films in general, are connected to the effects they produce, to movements that have an impact on us. Different images, whether from fiction or documentaries, merge in our mind and brains to produce new assemblages of environments and animals.

\section{REFERENCES}

Barrett, Estelle. 2012. "Materiality, Affect, and the Aethesthetic Image" in Carnal Knowledge, ed. Barret, Estelle \& Bolt, Barbara. London: I.B. Tauris.

Bousé, Derek. 2000. Wildlife Films. Philadelphia: University of Pennsylvania Press.

Cahill, James Leo. 2013. "Anthropomorphism and Its Vissitudes. Reflections on Hommesick Cinema" in Screening Nature. Cinema beyond Human, ed. Pick, Anat \& Narraway, Guinevere. London: Palgrave

Cottle, Simon. 2009. "Global Crises in the News: Staging New Wars, Disasters, and Climate Change." International Journal of Communication 3, 494-516.

Crylen, Jonathan Christopher. 2015. "Cinematic aquarium: a history of undersea film", PhD thesis, University of lowa, 2015. http://ir.uiowa.edu/etd/1839.

Cubitt, Sean. 2005. Ecomedia. Amsterdam: Rodopi.

Daston, Lorraine and Mitman, Greg. 2005. Thinking with Animals. New Perspective on Anthropomorphism. New York: Columbia University Press.

Deleuze, Gilles and Guattari, Felix. 2004. A Thousand Plateaus. London: Continuum. 
Dolphins - Spy in the Pod. 2014. Producer: John Downer Production Ltd.

Galloway, Alexander R. 2006. Gaming. Essays on Algorithmic Culture. Minneapolis: University of Minnesota Press.

Haraway, Donna. 2007. When Species Meet. Minneapolis: University of Minnesota Press.

Haraway, Donna. 2003. The Companion Species Manifesto. Chicago: Prickly Paradigm Press.

Herzogenrath, Bernd. 2008. "Introduction" in An (Un)likely Alliance: Thinking Environment(s)with Deleuze/Guattari, ed. Berzogenrath, Bernd. New Castle upon Tyne: Cambridge Scholars Publishing.

Ivakhiv, Adrian. 2012. "An Ecophilosophy of the Moving Image: Cinema as Anthrobiogeomorphic Machine" in Ecocinema Theory and Practice, ed. Rust, Stephen, Monani Salma \& Cubitt, Sean. GB: Routledge.

Jeffries, Michael. 2003. "BBC Natural History versus Science Paradigms”. Science as Culture. Vol. 12, Issue 4.

MacDonald, Scott. 2006. "Up Close and Political. Three Short Ruminations on Ideology in the Nature Film". Film Quarterly, Vol. 59, Issue 3, 4-21.

Messier, Vartan P. and Batra, Nandita. 2008. "Introduction. The Multitudinous Seas: Matter and Metaphor" in This Watery World. Humans and the Sea, ed. Messier, Varta P \& Batra, Nandita. New Castle upon Tyne: Cambridge Scholars Publishing.

Mitman, Greg. 1999. Reel Nature. America's Romance with Wildlife on Film. Seattle: University of Washington Press.

Oceans. 2008. Producer: BBC, Discovery Channel.

Past, Elena. 2009. "Lives aquatic: Mediterranean Cinema and an Ethics of Underwater Existence." Cinema Journal, 48, Number 3, Spring 2009, pp. 52-65

Planet Earth. 2006. Producer: BBC.

Pick, Anat and Narraway, Guinevere. 2013. "Introduction: Intersecting Ecology and Film" in Screening Nature. Cinema beyond the human, ed. Pick, Anat \& Narraway, Guinevere. New York: Berghahn Books.

Pisters, Patricia. 2003. The Matrix of Visual Culture. Working with Deleuze in Film Theory. Standford: Standford University Press.

Prescot-Steeds, David J. 2008. "Contemporary Mass Media Representations of the Abyssal Zone" in This Watery World. Humans and the Sea, ed. Messier, Varta P \& Batra, Nandita. New Castle upon Tyne: Cambridge Scholars Publishing.

Richards, Morgan. 2013. "Greening Wildlife Documentary" in Environmental Conflict and the Media, ed. Lester, Libby \& Hutchins, Brett. New York: Peter Lang. 
Shell, Hanna Rose. 2005. “Things under Water. E. J. Marey's Aquarium Laboratory and Cinema's Assembly." http://web.mit.edu/ hrshell/www/experimentsonfilm/docs/ MareyArticle_Shell.pdf

Starosielski, Nicole. 2012. "Beyond Fluidity: A Cultural History of Cinema under Water," in Ecocinema. Theory and Practice, ed. Rust, Stephen, Monani Salma \& Cubitt, Sean. New York: Routledge.

Steinberg, P.E. 2013. "Of Other Seas: Metaphors and Materialities in Maritime Regions." Atlantic Studies, 10:2, 156-169. 